\title{
Modification of Enamel Surface Morphology and Strength Using Nd:YAG Laser with Proper and Safe Parameters
}

\author{
Amera Alkaisi ${ }^{1}$ Salma B.A. Abdo ${ }^{1,2}$ \\ ${ }^{1}$ Department of Dentistry, Al Farabi University College, Baghdad, Iraq \\ 2 Dental Department, Mediclinic Hospitals Middle East, UAE and AI \\ Address for correspondence Salma B. A. Abdo, PhD, Dental \\ Farabi University College, Baghdad, Iraq \\ Department, Mediclinic Hospitals Middle East, P. O. Box 68339, Abu \\ Dhabi, UAE (e-mail: salma114@hotmail.com).
}

Eur J Gen Dent 2021;10:123-128.

\begin{abstract}
Objective The aim of this study was to determine the effect of a Nd:YAG laser on enamel surface morphology and hardness using different energies and pulses.

Materials and Methods Twenty freshly extracted mature teeth were collected and sectioned. An Nd:YAG laser operating at $1,064 \mathrm{~nm}$ wavelength and providing up to 9 nanosecond laser pulses (1 J), with a laser spot diameter of $0.8 \mathrm{~mm}$ and irradiated surface area of $3 \times 3 \mathrm{~mm}^{2}$, was applied to carbon black-coated teeth. The samples were randomly divided into two main groups; each group comprised 20 samples, according to the treatment parameters. The first group was further divided into subgroups A, B1, $C 1$, and D1 using the different energies of $0,350,450$, and $550 \mathrm{~m}$, respectively, with 1 pulse for $B 1, C 1$, and $D 1$. The second group was subdivided into $A, B 2, C 2$, and D2 and treated with $200 \mathrm{~mJ}, 3,4$, and 6 pulses for subgroups B2, C2 and D2, respectively. Subgroup A was the same sample for both groups as control with 0 pulses and 0 energy. Morphological features and microhardness were evaluated after laser exposure.

Statistical Analysis Analysis of variance (Kruskal-Wallis test) was used to compare all subgroups, followed by the Scheefy significant difference post hoc test to determine the highest significance of the subgroups. Alpha $<0.05$ was set as significant.

Results The changes in the surface morphology of the enamel included increased

Keywords

- enamel

- morphology

- pulses

- energy

- Nd:YAG crystal sizes, cracks, fissures, and voids with increasing energies and pulses. In group 1 , the microhardness was 405.6, 562.7, 612, and 637 for energies of $0,350,450$, and $550 \mathrm{~mJ}$, respectively. In group 2 , the microhardness was $405.6,673,866$, and 1,050 for $0,3,4$, and 6 pulses, respectively.

Conclusion The Nd:YAG laser is efficient for increasing the microhardness of the enamel surface with minimum morphological damage by applying low energy with more pulses.
\end{abstract}

DOI https://doi.org/ 10.1055/s-0041-1736378. ISSN 2278-9626.

\footnotetext{
(c) 2021. European Journal of General Dentistry. All rights reserved. This is an open access article published by Thieme under the terms of the Creative Commons Attribution-NonDerivative-NonCommercial-License, permitting copying and reproduction so long as the original work is given appropriate credit. Contents may not be used for commercial purposes, or adapted, remixed, transformed or built upon. (https://creativecommons.org/ licenses/by-nc-nd/4.0/)

Thieme Medical and Scientific Publishers Pvt. Ltd., A-12, 2nd Floor, Sector 2, Noida-201301 UP, India
} 


\section{Introduction}

Currently, laser therapies are widely used in medicine and dentistry as they allow for blood vessel welding that minimizes bleeding and enhances the clear operative field with excellent visualization during a surgical operation. ${ }^{1}$ Dental lasers can be used to reduce pain without requiring anesthesia, ${ }^{2}$ cause less edema, and allow for rapid healing and sterilization of the tissue in comparison with scalpels used in surgery. ${ }^{2}$ There are several types of lasers with specific features, such as wavelengths and spot sizes, which are important for specific applications., ${ }^{3,4}$ Currently, dental lasers can be used in diagnosis, composite curing, and photodisinfections. ${ }^{5}$ In addition, different types of lasers with a specific wavelength can be used to control bleeding in vascular lesions, biopsies, tumor excisions, second-stage implant recovery, temporomandibular joint surgeries, surgical treatment of lichen planus, gingival melanin pigmentation, oral dysplasia, mucocele, Ranula, epulis fissuratum, gingivoplasty, gingivectomy, frenectomy, pulp amputation, the removal of smear layers in root canal disinfection and the activation of tooth bleaching solutions. ${ }^{6-10}$ An Nd:YAG laser is recommended in pediatric dentistry to seal pits and fissures, increasing the acid resistance of primary enamel and preventing tooth decay. ${ }^{11-13}$

A unique property of lasers is their monochromaticity, which affects a specific type of tissue or compound without interfering with the others. ${ }^{14,15}$ The interaction between tissues and laser energy is mainly determined by the laser wavelength and the properties of the target tissue. However, laser parameters, energy density, power density, pulse repetition rate, pulse duration, and the mode of energy transfer to the tissue are selected by the operator according to the clinical case that is being treated. ${ }^{16}$

Each tissue has its special absorption property depending on its consistency and chromophore; melanin, hemoglobin, protein, and water are the main chromophores present in the mammalian tissue. Water is mainly absorbed by infrared light, while hemoglobin and melanin are absorbed by visible and ultraviolet light, respectively. Therefore, a wavelength that is highly absorbed by a specific region chromophore must be selected. ${ }^{14}$ The mechanisms of interaction between lasers and biological tissues are mainly photochemical, photoacoustic, and photothermic mechanisms. In the oral cavity, the soft tissue effect is based on the transformation of light energy into thermal energy, which in turn heats the target tissue to produce the desired effect. ${ }^{17}$ It was reported that most medical lasers act by heating the target tissue, and the effects of high-temperature laser application on soft tissue are sterilization, coagulation and hemostasis, incision and excision, ablation, and vaporization. ${ }^{18}$ In the hard tissue of teeth (enamel and dentin) and bone, the main effects are ablation and melting as well as the absorption of energy by hydroxyapatite in addition to water. ${ }^{14,17}$

Temperature elevation in the interaction site leads to water evaporation, rapid volumetric expansion, and hard tissue disintegration caused by the production of microexplosions. Irreversible damage to the vital pulp can occur if the temperature increase is more than $5.5^{\circ} \mathrm{C}$; as a result, care must be taken when using lasers in tooth substances. Therefore, preserving the odontoblast nuclei and the intracellular tissue composition after laser ablation is an important factor for the viability of cells. ${ }^{18}$ There are high variations in the energy, pulse frequency, and irradiation duration chosen in the literature. ${ }^{19}$ In this work, we studied the effect of an Nd: YAG laser on the enamel surface morphology and hardness with different energies and pulses to choose the best and safest parameters for its modification.

\section{Materials and Methods}

\section{Study Design}

A randomized controlled study was conducted in Technology University laboratories between May 2020 and January 2021.

\section{Sample Preparation}

Twenty freshly extracted mature, molar and premolar teeth with no active caries and periodontal disease were stored in $10 \%$ formalin. The teeth were placed in plastic molds with their buccal surfaces facing outward. Epoxy resin was slightly warmed to solidify rapidly, mixed with a small amount of epoxy hardener, and poured on the teeth until the epoxy became solid. The molds were lifted. The teeth were sectioned either longitudinally or transversely using a lowspeed diamond wheel saw (Model SYJ-150, MTI Corporation) under water cooling. The samples were polished under water spray cooling using a grinding machine (grinder polisher MPD 200 Dual Speed Polisher, Laree Technology Co. Ltd., China) at rotating speeds between 150 and $300 \mathrm{r} / \mathrm{min}$ and Amery silicon carbide papers no. 1200 to 3000 . At the final polishing stage, a cloth and 0.05 polishing alumina were utilized in a metallurgical polisher (DP-U4; Struers, Denmark) at a low speed, with a light load on the samples. The samples were cleaned ultrasonically (Laboratory Tech, Daihan Labtech Co., Ltd., model LUC-410, Korea) in distilled water for 5 minutes and stored in distilled water at room temperature.

\section{Lasing Procedures}

A Q-switched Nd:YAG laser supplied by HUAFEL (Single pulse mode, China), operating at $1064 \mathrm{~nm}$ wavelength and providing up to 9 nanosecond laser pulses $(1 \mathrm{~J})$, was employed to irradiate the tooth enamel surfaces. A positive lens of $10 \mathrm{~cm}$ focal length was used to obtain the required laser energy fluence on the enamel surface, with a laser spot diameter of $0.8 \mathrm{~mm}$, which was checked by making a burn mark on carbon paper and viewed by an optical microscope. Irradiated surface areas of $3 \times 3 \mathrm{~mm}^{2}$ were performed on carbon black-coated tooth surfaces to enhance laser absorption. Alternatively, each sample was placed in a beaker containing black ink-water solution at a level slightly higher than the sample surface. Thirty-five samples were randomly divided into two main groups; each group comprised 20 samples, according to the treatment parameters, with 5 for each subgroup (Subgroup A was the same sample for both groups as control with 0 pulses and 0 energy). The first group was 
labeled with different laser energy level treatments. This group was subdivided into four subgroups A, B1, C1, and D1 using different energies of $0,350,450$, and $550 \mathrm{~mJ}$, respectively, with 1 pulse for $\mathrm{B} 1, \mathrm{C} 1$, and D1. The second group was subdivided into four subgroups A, B2, C2, and D2, which were treated with $200 \mathrm{~mJ}$ energy and different numbers of pulses; 3,4 , and 6 pulses were used for subgroups B2, C2, and D2, respectively. The subgroup (A) in each main group was the control group (untreated samples).

\section{Evaluations}

\section{Observations of Morphological Changes}

Two samples from each group were gold-coated for scanning electron microscope analysis using a scanning electron microscope (SEM) (Tescan, vega3, Czech) to observe structural changes in the enamel surfaces after each treatment in comparison with the non-treated one.

\section{Vickers Microhardness Tests}

A digital Micro Vickers hardness tester (TH 715, 2008, China) equipped with a high-resolution optical microscope was used to evaluate the surface modifications by a laser under $500 \mathrm{~g}$ loads and 15-second indentation conditions.

\section{Statistical Analysis}

SPSS version 25 software was used for data analysis, in which nonparametric analysis of variance (ANOVA) (Kruskal-Wallis test) was used to compare all subgroups followed by the Scheefy significant difference post hoc test to determine the highest significance of subgroups. Alpha $<0.05$ was set as significant.

\section{Results}

\section{Scanning Electron Microscopy Results}

\section{Morphology}

After exposure to the Nd:YAG laser, remarkable changes in the enamel surface were observed by SEM and these changes increased with increasing energy or pulses.

\section{Group 1}

Subgroup A: SEM image of subgroup A, $0 \mathrm{~mJ}$ and 0 pulse (control) showed normal smooth enamel with well-defined circumferentially arranged enamel rods filled with interrod material on the surface and depressions.

Subgroup B1: SEM image of subgroup B1 (350 mJ, one pulse). The enamel features were seen clearly with minimum alteration in the morphology despite the presence of a few cavitations and fissures.

Subgroup C1: SEM image of subgroup C1 (450 mJ, one pulse). Alterations in enamel morphology, melting enamel with the presence of enamel granules, holes, and fissures were observed.

Subgroup D1: SEM image of subgroup D1 (550 mJ, one pulse) showed a complete change in features. A glass-like appearance with melted smooth enamel surfaces was observed. Large cracks and fissures were seen.

\section{Group 2}

Subgroup B2: SEM image of subgroup B2, $200 \mathrm{~mJ}$ and 3 pulses. The sample appeared uniform, the enamel surface was smooth and homogenous with well-coalesced enamel rods; there were a few cavities and cracks.

Subgroup C2: SEM image of subgroup $200 \mathrm{~mJ}$ and 4 pulses showed melted enamel with large granules and fine fissures

Subgroup D2: The SEM image of subgroup D2 (200 mJ and 6 pulses) appeared rough and nonuniform with the fusion of granules; there was an appearance of cracks and cavities with small smooth areas (-Figs. 1 and $\mathbf{2}$ ).

\section{Vickers Microhardness}

-Figs. 3-5 show the increase in microhardness with increasing energy and pulses. The increase in the hardness was higher with the increase in pulses than with the increase in energy.

\section{Statistical Analysis}

Generally, there were highly significant differences between all subgroups $(p<0.001)$ ( - Table 1 ). There was a significant difference between group A and DI, B2, C2, and D2, with $p=0.023,0.003,<0.001$, and $<0.001$, respectively. However, there were no significant differences between group $A$ and groups B1 and C1, $p=0.264$ and 0.058 , respectively, in group B1. Interestingly, there was no significant difference between D1 and B2, $p=0.988$, although high energy was used in D1 (550 $\mathrm{mJ})$ and lower energy was used in B2 $(200 \mathrm{~mJ})$.
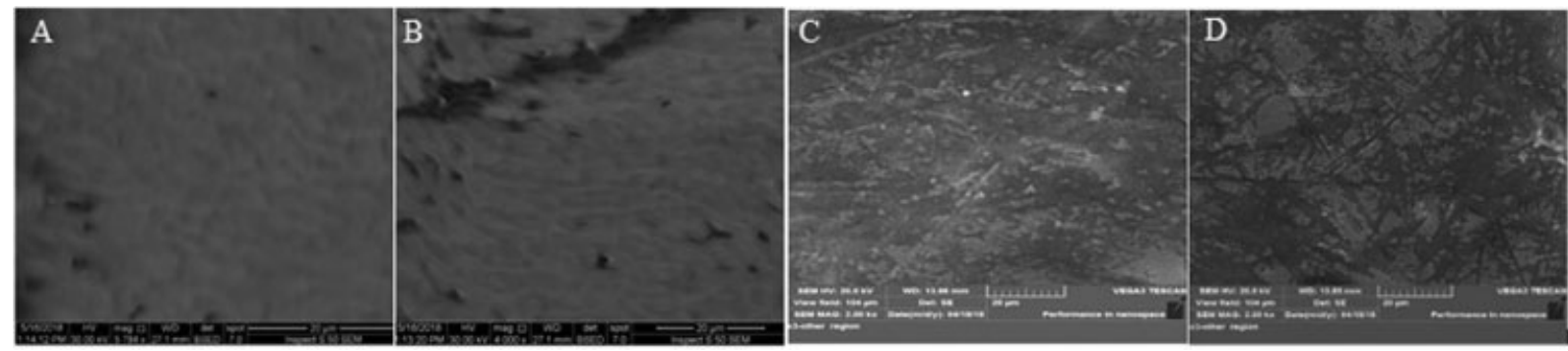

Fig. 1 Scanning electron microscopy of 0 and 1 pulses with different energies: (A) SEM image of subgroup A, 0 mJ and 0 pulse (control), magnification, $5.784 \mathrm{k} \times$. (B) SEM image of subgroup B1, $350 \mathrm{~mJ}$, one pulse, magnification, $4.00 \mathrm{k} \times$. (C) SEM image of subgroup C1, $450 \mathrm{~mJ}$, one pulse, magnification, $2.00 \mathrm{k} \times$. (D) SEM image of subgroup D1, $550 \mathrm{~mJ}$, one pulse, magnification $2.00 \mathrm{k} \times$. 

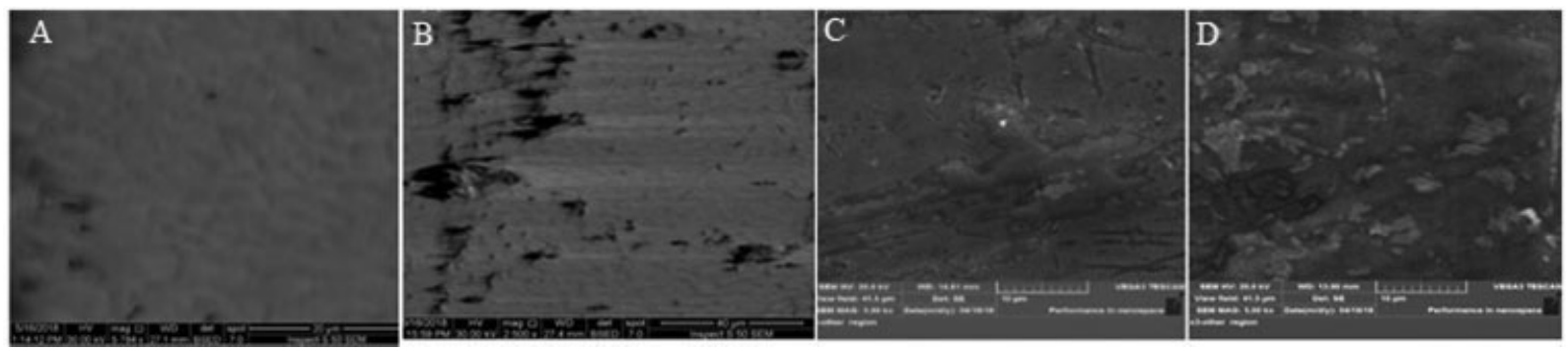

Fig. 2 Scanning electron microscopy image of constant energy with different pulses: (A) SEM image of subgroup A, 0 mJ and 0 pulses (control), magnification, $5.784 \mathrm{k} \times$. (B) SEM image of subgroup B2, $200 \mathrm{~mJ}$ and 3 pulses, magnification $2.500 \mathrm{k} \times$. (C) SEM image of subgroup $200 \mathrm{~mJ}$ and 4 pulses, magnification, $5.00 \mathrm{k} \times$. (D) SEM image of subgroup D2, $200 \mathrm{~mJ}$ and 6 pulses, magnification $5.00 \mathrm{k} \times$.

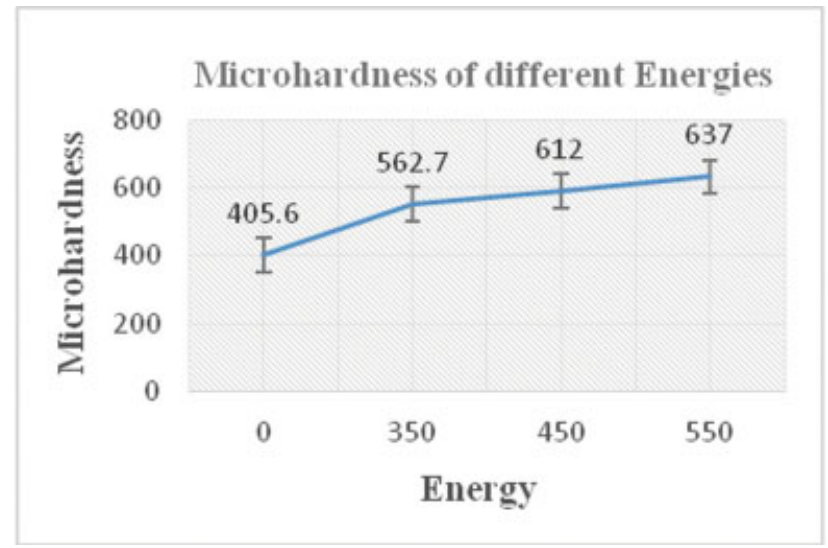

Fig. 3 Microhardness of different energies.

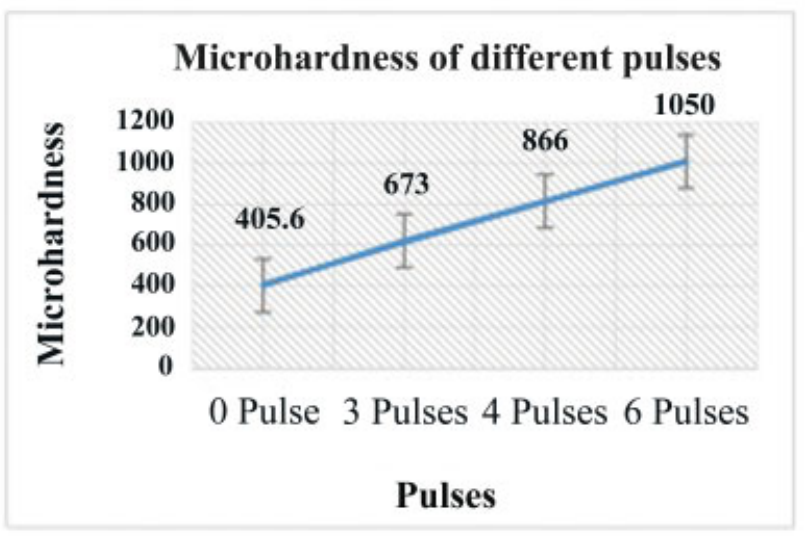

Fig. 4 Microhardness of different pulses.

\section{Discussion}

The use of laser beams in the treatment of dental hard tissues has recently gained acceptance, and a precise irradiation parameter must be selected for clinical application to avoid morphological damage in the form of surface carbonization or cracking that destroys the structure and esthetics. Safe energy densities must be chosen to protect the pulp and periodontal tissue vitality, and short pulses must be used to prevent thermal damage to the irradiated surface. ${ }^{20-23}$ One study reported that the chosen area could be targeted and

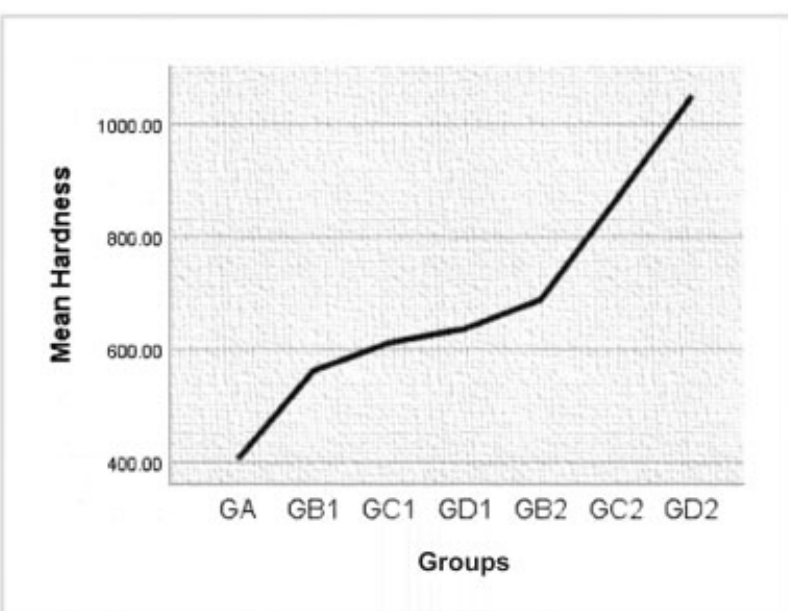

Fig. 5 Microhardness of all subgroups.

Table 1 Statistical analysis results

\begin{tabular}{|l|l|}
\hline Test Statistics & \\
\hline & Hardness \\
\hline Kruskal-Wallis H & 30.583 \\
\hline$D_{\mathrm{f}}$ & 6.000 \\
\hline Asymp. Sig. & 0.000 \\
\hline
\end{tabular}

${ }^{\mathrm{a} K r u s k a l-W a l l i s ~ t e s t . ~}$

${ }^{\mathrm{b}}$ Grouping variable.

that the surrounding tissue was relatively unaffected. ${ }^{14}$ In the current study, we limit the energy to $550 \mathrm{~mJ}$ according to our previous study, in which we found that energy higher than $600 \mathrm{~mJ}$ damaged the enamel surface with cracks. ${ }^{24}$

\section{Morphologic Features}

In the current study, different changes were observed in the morphology of all subgroups in comparison with the control after using different energies and pulses. Al-Jedani et al characterized the normal enamel surface by the presence of enamel rods and depressions with dentinal tubules extending from the pulp outward through the dentin to the external enamel surface. ${ }^{25}$ Several authors agree with our finding; they reported that the exposure of enamel to a laser beam altered its morphology. SEM results showed 
different morphologic features, cracks, and holes in the irradiated surface depending on the intensity of the radiation and number of pulses when more changes were seen. ${ }^{25,26}$ These alterations in the surface appear as a result of melting, followed by enamel recrystallization during cooling, and the authors observed that the alterations occurred only in the enamel surface layers as the section taken perpendicular to it and that no changes occurred in the enamel crystals on the internal side of the tooth. ${ }^{26}$

Altering the composition and morphology of enamel requires strong absorption of light, and more absorption of radiation by the target tissue decreases the depth of light penetration. ${ }^{24,27}$ In this study, an Nd:YAG laser was used, which was weakly absorbed by enamel; therefore, the tooth surface was coated with carbon black, which acts as a photoabsorber, to increase the absorption of the laser and decrease the thermal damage to the adjacent tissues. One study used waterproof India ink, which is commonly applied onto enamel surfaces before Nd:YAG laser irradiation, to serve as a photoabsorber. ${ }^{25,28}$ The use of a photoabsorber is recommended before Nd:YAG laser application; otherwise, incomplete absorption of the light by the enamel surface leads to reflection scattering or transmission to the dentin and pulp, which compromise its vitality. ${ }^{28,29}$

The predominant mechanism of the nanosecond laser pulse as described by Lee is that when the intensity is less than $108 \mathrm{~W} / \mathrm{cm}^{2}$, an increase in the temperature of the solid surface, thermal vaporization, and phase transition occurs from solid to liquid, vapor, and plasma, respectively. ${ }^{27,30}$ Columns separated by voids are the result of enamel melting and then solidification, and the strongest morphological changes occur when a higher energy density or a higher number of pulses are used. ${ }^{25}$ Fissures appear on the enamel surface due to sudden and rapid changes in temperature, and they cannot be distributed due to the tight structure of the enamel that lacks porosities, which damages the enamel. ${ }^{31}$

It was reported that the increase in temperature on dental tissues, generated by irradiation, is responsible for the change in the morphology and structure of the irradiated surface, and temperature changes are extremely high at the irradiated spot, even for a short exposure time. ${ }^{32,33}$

Several authors stated that the effect of high temperature produced by Nd:YAG irradiation is the formation of tricalcium phosphate (TCP) $\mathrm{Ca}_{3}\left(\mathrm{PO}_{4}\right)_{2}$ on enamel ${ }^{34}$ and changes in the organic matrix, chemical, crystallographic aspects, and morphology. ${ }^{26,35,36}$

A study concluded that the structure and chemical composition of dental enamel are changed when the temperature increases. These alterations include a decrease in carbonate, loss of water, pyrophosphate formation by condensation of acid phosphate ions, thermal recrystallization, and increases in the crystal size and TCP formation. ${ }^{35}$ Hydroxyapatite becomes less soluble when the amount of carbonate decreases because carbonate causes defects in the crystal such that it does not fit into the lattice, generating more acidsoluble apatite unstable phases. Pyrophosphate inhibits hydroxyapatite crystal dissolution, while tri- and tetracalcium phosphates are more susceptible to acid dissolution than hydroxyapatite. Additionally, organic matrix decomposition increases tooth enamel resistance to acid, closes the pores of the enamel, and prevents the penetration of acid ions. $^{36,37}$

\section{Microhardness}

This study observed a significant increase in microhardness in all groups with increasing energy and pulses. This result is in agreement with that reported by Florin et al, who observed an increase in enamel microhardness after laser irradiation. ${ }^{38}$ We believe that we used energy within a safe range that did not lower the microhardness of our samples, as our results showed minimum alteration in the morphology of the enamel in the $350 \mathrm{~mJ}$ and 3 pulse subgroups. Morphological changes increase with increasing energy and pulse. These increased morphological changes were associated with an increase in microhardness, and none of the subgroups showed a decrease in microhardness with an increase in morphology alteration.

However, several authors found that the increase in radiation intensity decreases the solubility in lactic acid associated with a reduction in enamel hardness, which may be due to column-shaped crack and void formation. ${ }^{19,39,40}$ One study observed that microhardness decreased in irradiated specimens, ${ }^{26}$ while another study reported no alteration in microhardness after laser irradiation. ${ }^{41}$ They concluded that the difference between the authors' results was due to different parameter settings, wavelengths, methodologies, and the use of primary or permanent teeth. ${ }^{41}$

\section{Conclusion}

The Nd:YAG laser is efficient for modifying the enamel surface by increasing its microhardness with minimal morphological changes. We found that increasing pulses rather than increasing energy is beneficial. A specific parameter must be selected to reach the treatment goal by concentrating on the target area without damaging the nearby structures; therefore, we recommend an in vivo study to confirm the safety of this parameter setting in living tissue.

\section{Conflict of Interest}

None declared.

\section{References}

1 Sulieman M. An overview of the use of lasers in general dental practice: 1 . Laser physics and tissue interactions. Dent Update 2005;32(04):228-230, 233-234, 236

2 Kim KS, Kim ME, Shin EJ. Irradiation time and ablation rate of enamel in contact and non-contact irradiation with Er:YAG laser. Photomed Laser Surg 2005;23(02):216-218

3 Golnabi H, Mahdieh MH. Trend of laser research developments in global level. Optics \& Laser Tchnology 2006;38(02):122-131

4 Deppe H, Horch HH. Laser applications in oral surgery and implant dentistry. Lasers Med Sci 2007;22(04):217-221

5 Fantarella D, Kotlow L. The $9.3-\mu \mathrm{m} \mathrm{CO}_{2}$ dental laser: technical development and early clinical experiences. J Laser Dent 2014;22 (1):10-27 
6 Sulieman M. An overview of the use of lasers in general dental practice: 2. Laser wavelengths, soft and hard tissue clinical applications. Dent Update 2005;32(05):286-288, 291-294, 296

7 Abdo S, Alkaisi A, Saleem M, Zetouni J. Clinical applications of lasers in Endodontic. J Dent Res 2018;1:7-15

8 Oviya M. Eapen BV, Ganapathy D. A review on usage of laser in oral surgery. Eur J Mol \& Clin Med 2021;08(01):431-440

9 Butchibabu K, Koppolu P, Mishra A, Pandey R, Swapna LA, Uppada UK. Evaluation of patient perceptions after labial frenectomy procedure: a comparison of diode laser and scalpel techniques. Eur J Gen Dent 2014;3(02):129-133

10 Reza B, Mohsen HS, Elham F, Mina N, Sara N, Ehsan B. Evaluation of root canal smear layer removal by two types of lasers: a scanning electron microscopy study. Eur J Gen Dent 2013;2(02): 151-157

11 Banda NR, Vanaja Reddy G, Shashikiran ND. Evaluation of primary tooth enamel surface morphology and microhardness after Nd: YAG laser irradiation and APF gel treatment-an in vitro study. J Clin Pediatr Dent 2011;35(04):377-382

12 Azevedo DT, Faraoni-Romano JJ, Derceli JdosR, Palma-Dibb RG. Effect of Nd:YAG laser combined with fluoride on the prevention of primary tooth enamel demineralization. Braz Dent J 2012;23 (02):104-109

13 Correa-Afonso AM, Pécora JD, Palma-Dibb RG. Influence of laser irradiation on pits and fissures: an in situ study. Photomed Laser Surg 2013;31(02):82-89

14 Nishidate I, Aizu Y, Mishina H. Estimation of melanin and hemoglobin in skin tissue using multiple regression analysis aided by Monte Carlo simulation. J Biomed Opt 2004;9(04):700-710

15 Weiner GP. Laser dentistry practice management. Dent Clin North Am 2004;48(04):1105-1126, ix

16 Dederich DN. Laser/tissue interaction: what happens to laser light when it strikes tissue? J Am Dent Assoc 1993;124(02):57-61

17 Parker S. Verifiable CPD paper: laser-tissue interaction. Br Dent J 2007;202(02):73-81

18 Lizarelli RFZ, Moriyama LT, Bagnato VS. Temperature response in the pulpal chamber of primary human teeth exposed to Nd:YAG laser using a picosecond pulsed regime. Photomed Laser Surg 2006;24(05):610-615

19 Kuramoto Júnior M, Matson E, Turbino ML, Marques RA. Microhardness of Nd:YAG laser irradiated enamel surfaces. Braz Dent J 2001;12(01):31-33

20 McDonald AV, Claffey NM, Pearson GJ, Blau W, Setchell DJ. Effect of $\mathrm{Nd}$ :YAG radiation at millisecond pulse duration on dentine crater depth. Lasers Surg Med 2000;27(03):213-223

21 Nammour S, Kowalyk K, Valici C, et al. Safety parameters for pulp temperature during selective ablation of caries by KTP laser in vitro. J Clin Laser Med Surg 2004;22(02):99-104

22 Ana PA, Bachmann L, Zezell DM. Laser effects on enamel for caries prevention. Laser Phys 2006;16:865https://doi.org/10.1134/ S1054660X06050197

23 Ana PA, Blay A, Miyakawa W, Zezell DM. Thermal analysis of teeth irradiated with Er,C:YSGG laser at low fluences. Laser Phys Lett 2007;4:827-830
24 Shakir ZS, Alkaisi AK. Nd:YAG laser enhance dental enamel resistance to demineralization preventing dental caries. GJRA 2019;8(07):157-159

25 Al-Jedani S, Al-Hadeethi Y, Ansari MS, Razvi MAN. Dental hard tissue ablation with laser irradiation. Austin Dent Sci 2016;1 (1):1007

26 Tagomori S, Iwase T. Ultrastructural change of enamel exposed to a normal pulsed Nd-YAG laser. Caries Res 1995;29(06): 513-520

27 Tsai CL, Lin YT, Huang ST, Chang HW. In vitro acid resistance of $\mathrm{CO}_{2}$ and Nd-YAG laser-treated human tooth enamel. Caries Res 2002; 36(06):423-429

28 Jennett E, Motamedi M, Rastegar S, Frederickson C, Arcoria C, Powers JM. Dye-enhanced ablation of enamel by pulsed lasers. J Dent Res 1994;73(12):1841-1847

29 Gelskey SC, White JM, Gelskey DE, Kremers W. Vapor emissions resulting from Nd:YAG laser interaction with tooth structure. Dent Mater 1998;14(06):453-457

30 Armengol V, Jean A, Marion D. Temperature rise during Er:YAG and Nd:YAP laser ablation of dentin. J Endod 2000;26(03): 138-141

31 Hossain M, Nakamura Y, Yamada Y, Kimura Y, Matsumoto N, Matsumoto K. Effects of Er,Cr:YSGG laser irradiation in human enamel and dentin: ablation and morphological studies. J Clin Laser Med Surg 1999;17(04):155-159

32 Kwon YH, Lee JS, Choi YH, Lee JM, Song KB. Change of enamel after Er:YAG and $\mathrm{CO} 2$ laser irradiation and fluoride treatment. Photomed Laser Surg 2005;23(04):389-394

33 Bedini R, Manzon L, Fratto G, Pecci R. Microhardness and morphological changes induced by Nd:Yag laser on dental enamel: an in vitro study. Ann Ist Super Sanita 2010;46(02):168-172

34 Antunes A, de Rossi W, Zezell DM. Spectroscopic alterations on enamel and dentin after nanosecond Nd:YAG laser irradiation. Spectrochim Acta A Mol Biomol Spectrosc 2006;64(05): 1142-1146

35 Fowler BO, Kuroda S. Changes in heated and in laser-irradiated human tooth enamel and their probable effects on solubility. Calcif Tissue Int 1986;38(04):197-208

36 Bachmann L, Baffa O, Gomes ASL, Zezell DM. Chemical origin of the native ESR signals in thermally treated enamel and dentin. Physica B 2004;349:119-123

37 Liu Y, Hsu CYS. Laser-induced compositional changes on enamel: a FT-Raman study. J Dent 2007;35(03):226-230

38 Florin R, Herrmann C, Bernhardt W. Measuring microhardness of laser exposed tooth surface [Article in German]. Stomatol DDR 1990;40(02):49-51

39 Oho T, Morioka T. A possible mechanism of acquired acid resistance of human dental enamel by laser irradiation. Caries Res 1990;24(02):86-92

40 Márquez F, Quintana E, Roca I, Salgado J. Physical-mechanical effects of Nd:YAG laser on the surface of sound dental enamel. Biomaterials 1993;14(04):313-316

41 Majori M, Manzon L, Pane S, Bedini R. Effects of Nd:YAG laser on dental enamel. J Appl Biomater Biomech 2005;3(02):128-133 